\title{
Görsel yürüme analizi
}

\author{
Visual assessment of gait
}

\author{
Sebahat Aydil', Pınar Özkan¹, Kubilay Beng² \\ ${ }^{1}$ Baltalimanı Kemik Hastalıkları Eğitim ve Araştırma Hastanesi, Yürüme Analizi Laboratuvarı, İstanbul \\ ${ }^{2}$ Baltalimanı Kemik Hastalıkları Eğitim ve Araştırma Hastanesi, İstanbul
}

\begin{abstract}
Görsel yürüme analizi, serebral palsi gibi nöromusküler hastalıklarda değerlendirmenin önemli bir parçasıdır. Görsel yürüme analizi birçok durumda üç boyutlu yürüme analizine alternatif olarak kullanılmaktadır. Altın standart olan üç boyutlu yürüme analizinin yerini tutmasa da kolay erişilebilir ve uygulanabilir olması, kayıtların tekrar tekrar alınmasına olanak sağlaması nedeniyle klinik takipte etkinliği kanıtlanmış bir yöntemdir.
\end{abstract}

Anahtar sözcükler: yürüme; çözümleme; gözlem
Visual assessment of gait is an essential element in the evaluation of ambulant children with neuromuscular diseases such as cerebral palsy. Visual gait analysis is used as an alternative to three-dimensional gait analysis in a number of settings. While it does not substitute for gold standard three-dimensional gait analysis, it can prove to be a useful tool in the clinical follow-up of patients due to its availability, ease of use, and the possibility of repeated recordings.

Key words: gait; analysis; observation
Y ürüme analizi; yürüme problemlerinin değerlendirilmesinde fizik muayene ve diğer tanısal testlere yardımcı bir yöntemdir. Normal yürümeden sapmaların objektif olarak değerlendirilmesinde, tanı koymada ve uygun tedavinin belirlenmesinde önemli bir yer tutmaktadır.

Yürümeyi değerlendirmede üç boyutlu bilgisayarlı yürüme analizi altın standarttır, görsel yürüme analizi ise klinik bir değerlendirmedir. Görsel yürüme analizi üç boyutlu bilgisayarlı yürüme analize göre daha subjektif bir değerlendirme imkanı sunar. Aynı anda farklı eklemlerde, üç boyutlu hareketlerden oluşan yürümenin insan gözüyle tespit edilmesi oldukça zordur. Bu nedenle görsel yürüme analizinin başarısı ve güvenilirliği gözlemi yapan kişinin deneyimlerine bağlıdır ve primer patolojiler ile bu patolojilere sekonder gelişen kompansatuvar mekanizmaların ayrımı oldukça zordur. ${ }^{[1]}$

Gözleme dayalı analiz, daha gelişmiş bir teknik olarak, video tabanlı kayıtlar alınarak yapılabilir. Video tabanlı görsel analiz, farklı açılardan alınan kayıtların ağır çekimde izlenmesi ve kareleri dondurma özelliği sayesinde, çıplak gözle yapılan gözleme göre daha avantajlıdır. Video tabanlı kayıtlar görsel yürüme analizi için özel olarak ayrılmış bir alanda yapılmalıdır. Kayıtlar alınırken, yürümesi değerlendirilecek hasta sadece iç çamaşıı ile olmalıdır. Kayıtlar önden, arkadan ve her iki yandan yapılmalıdır. Kayıtlar sırasında hastanın günlük yürüme paterninde ve hızında yürümesi önemlidir. Hasta öncelikle çıplak ayakla yürütülmeli ve sonrasında, varsa ortezi ve ayakkabısı ile yürütülmelidir. Bu şekilde ortezlerin etkinliği de değerlendirilebilir. Genellikle video kayıtları 1-2 dk süreyle alınır; nadiren $3 \mathrm{dk}$ üzerinde çekim yapılır. Bu kayıtların saklanması gereklidir. Bu şekilde her vizitte yeni kayıtlarla beraber eski kayıtlar da izlenebilmeli ve ilk değerlendirme ile yeni yapılan değerlendirme arasındaki değişiklikler kaydedilmelidir. Eğer görsel yürüme analizi yapılacak hasta 3 yaş altında ise 6 ayda bir, 3-12 yaş arasında ise 12 ayda bir, 12 yaş üzerinde ise $2-3$ yılda bir kayıt alınmalıdır. ${ }^{[2]}$ Bu süreler her hasta için ayrı ayrı belirlenmeli ve muayene sırasında önceki muayenelere göre bir değişiklik fark edildiğinde yeni kayıtların alınması gereklidir.

Yürümeyi değerlendirirken en önemli zorluk birincil patoloji ile hastanın geliştirdiği kompansatuvar mekanizmaların ayırt edilmesidir. Bu ayrım için, görsel

- Illetişim adresi: Dr. Sebahat Aydil, Metin Sabancı Baltalimanı Kemik Hastalıkları Eğitim ve Araştırma Hastanesi, Yürüme Analizi Laboratuvarı, Rumelihisarı cad. No: 62, Baltalimanı, Sarıyer, İstanbul Tel: 0212 - 3237075 e-posta: drsebahataydil@yahoo.com

- Geliș tarihi: 23 Temmuz 2014 Kabul tarihi: 23 Temmuz 2014 
yürüme analizi sistematik, kapsamlı ve ayrıntılı olarak yapılmalıdır. Bunun için yürüme alt fazlara ayrılarak sagittal, frontal ve transvers planlardaki gövde, kalça, diz ve ayak bileği eklemlerinin pozisyonları ile adım uzunluğu gibi zaman-mesafe parametreleri değerlendirilmelidir: ${ }^{[3]}$

\section{SAGITTAL PLAN}

1. ilk Temas: Kalçada yaklaşık $30^{\circ}$ fleksiyon olmalıdır. Kalçada ilk temasta artmış fleksiyon varsa psoas spastisitesi veya kontraktürü, abdominal kaslarda zayıflık akla gelmelidir.

Diz ilk temasta tam ekstansiyon veya $5^{\circ}$ fleksiyonda olmalıdır. Eğer ilk temasta dizde artmış fleksiyon varsa diz fleksiyon kontraktürü, hamstring spastisitesi veya ayak plantarfleksör spastisitesine sekonder gelişen kompansatuvar mekanizma düşünülmelidir. Ayak bileği ilk temasta nötral pozisyonda olmalı ve yere ilk olarak topuk temas etmelidir. Ayak plantarfleksörler spastisitesinde veya ayak dorsifleksör zayıflığında ayak ilk teması ön ayak veya tüm taban ile yapar (Şekil 1). ${ }^{[3,4]}$

2. Yüklenmenin Kabulü: Bu fazda vücut ağırlığının aktarılmasıyla oluşan şokun absorpsiyonu için dizde yaklaşık olarak $20^{\circ}$ fleksiyon olmalı ve ayak yere tamamen temas etmelidir. Eğer diz ağrısı veya kuadriseps kas zayıflığı varsa yüklenmenin kabulü fazında diz yeterli fleksiyona gitmez ve ekstansiyonda kalır (Şekil $2) \cdot{ }^{[3,4]}$

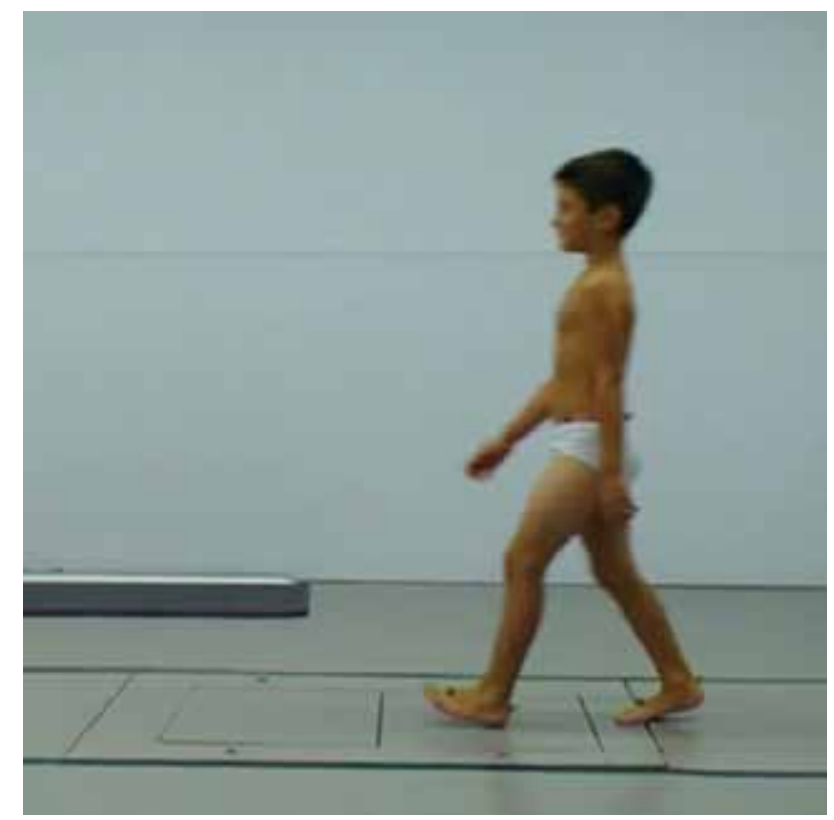

Şekil 1. ilk temas.
3. Basma ortası: Kalça ve diz ekstansiyonda, ayak bileği ise $10^{\circ}$ dorsifleksiyondadır. Vücut ağırlık merkezi kalça ve diz ekleminin ortasından geçtiği için kas aktivitesine ihtiyaç olmadan kalça ve diz ekleminde stabilite sağlanmış olur. Bu fazda bükük diz yürüyüşü ya da genu rekürvatum varlığı gözlenmelidir. Basma ortası fazda erken topuk kalkışı varsa gastroknemius spastisitesi, dorsifleksiyon kısıtlılığı veya ekin deformitesi akla gelmelidir (Şekil 3). ${ }^{[2,3,4]}$

4. Basma sonu: Kalçada maksimum ekstansiyon olmalıdır. Eğer kalça maksimum ekstansiyona gitmiyorsa kalça fleksör spastisitesi veya kontraktür varlığı değerlendirilmelidir (Şekil 4).

5. Salınım öncesi: Ayak bileğinde hızlı bir şekilde $20^{\circ}$ plantarfleksiyon oluşur ve vücudun öne ilerletilmesi için gerekli olan gücün önemli bir kısmını sağlar. İtme gücünün geriye kalan kısmı ise kalça fleksörleri tarafından sağlanır. Dizde ise pasif fleksiyon olur. Plantarfleksör kas zayıflı̆̆ı veya spastisitesi, kalça fleksör zayıflığında salınım öncesi fazdaki itme gücü azalır (Şekil 5). ${ }^{[3]}$

6. ilk salınım: Salınım fazında diz $60-70^{\circ}$ 'lik fleksiyon yapmakta ve ayağın yerden teması kesilmektedir. illk salınım fazında yetersiz diz fleksiyonu rektus femoris spastisitesini ve sert dizi düşündürür. Salınım fazında ayağın yerden temasının kesilmemesi ayak dorsifleksör zayıflığının ve stepaj yürüyüşünün göstergesidir (Şekil 6). ${ }^{[4]}$

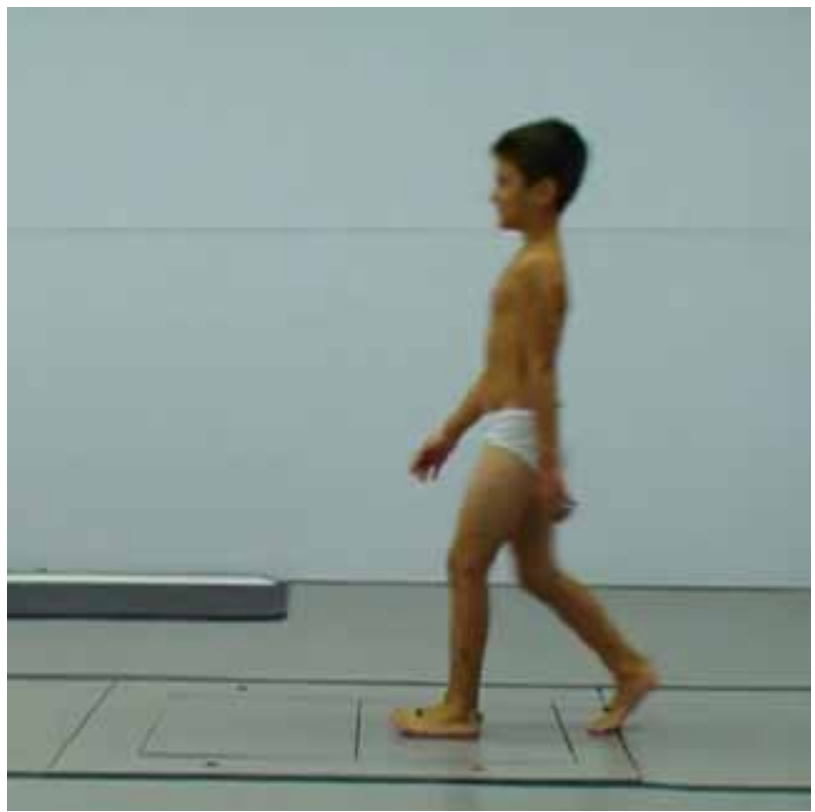

Şekil 2. Yüklenmenin kabulü. 
7. Salınım ortası: Salınan taraftaki bacak basma fazındaki bacağın önüne geçer. Kalça ve dizdeki fleksiyon atalet etkisiyle olurken, ayak dorsifleksörleri kasılmaya devam ederek ayağın yere değmeden öne doğru ilerletilmesini sağlar (Şekil 7).

8. Salınım sonu: Ayak; topuk ilk teması yapacak şekilde basmaya hazırlanır. Yeterli adım uzunluğunun sağlanması için diz tam ekstansiyona gider. Salınım

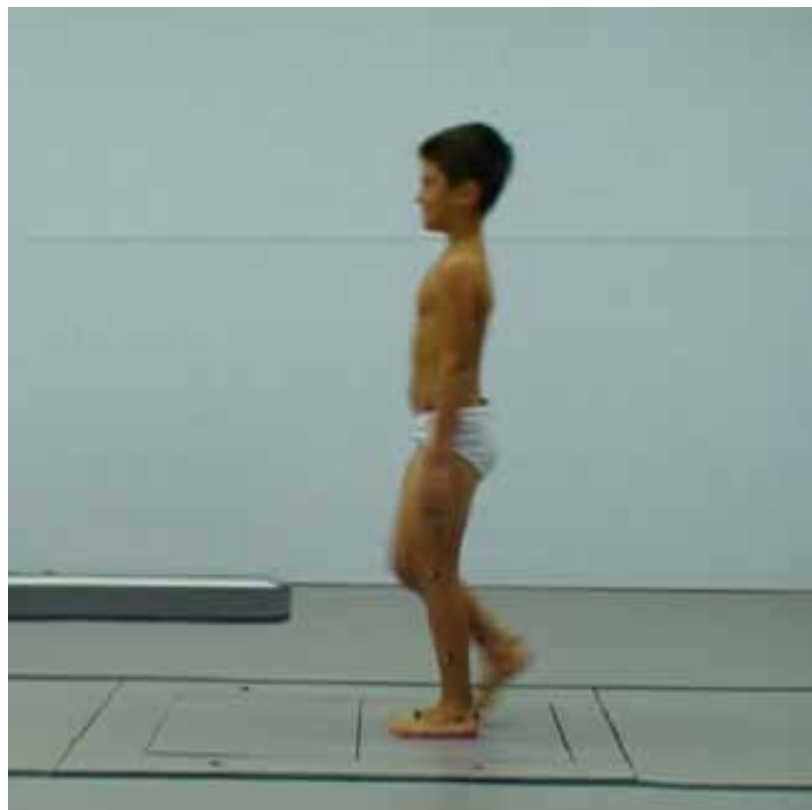

Şekil 3. Basma ortası.

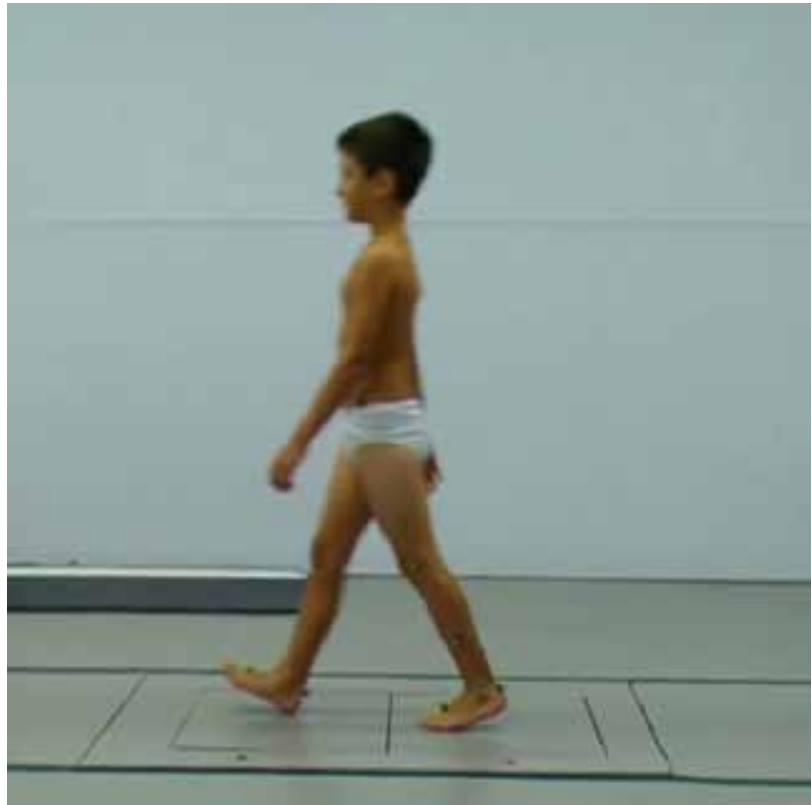

Şekil 5. Salınım öncesi. sonu fazında yetersiz diz ekstansiyonu diz fleksiyon kontraktürünü veya spastisitesini düşündürür (Şekil 8).

9. Gövde: Sagittal planda gövdenin öne doğru eğilmesi; birçok patolojik yürüyüşte gözlenen kompansatuvar mekanizmadır. Gövdenin öne eğilmesi ile vücut ağırlık merkezi diz ekleminin önünden geçer ve dizde kuadriseps aktivitesine gerek olmadan stabilite sağlanır ve kuadriseps zayıflığı kompanse edilir. ${ }^{[3,4]}$

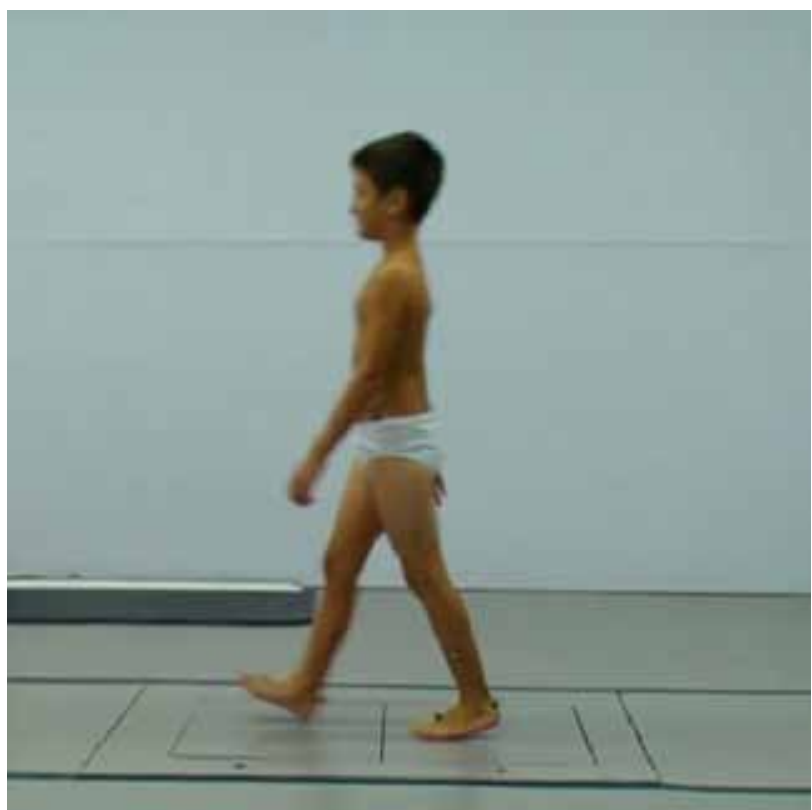

Şekil 4. Basma sonu.

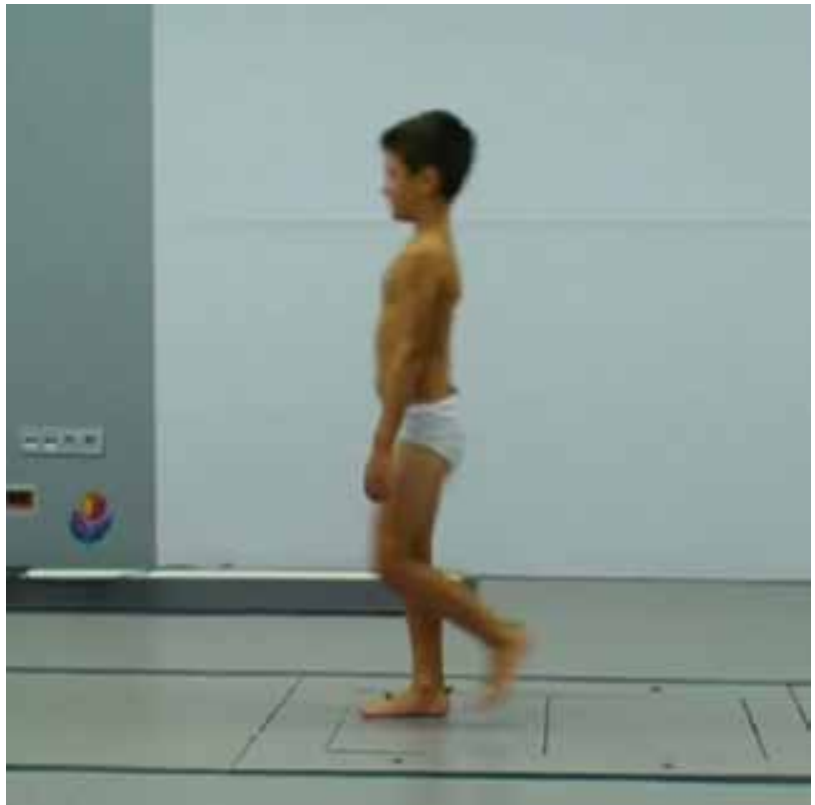

Şekil 6. illk salınım. 


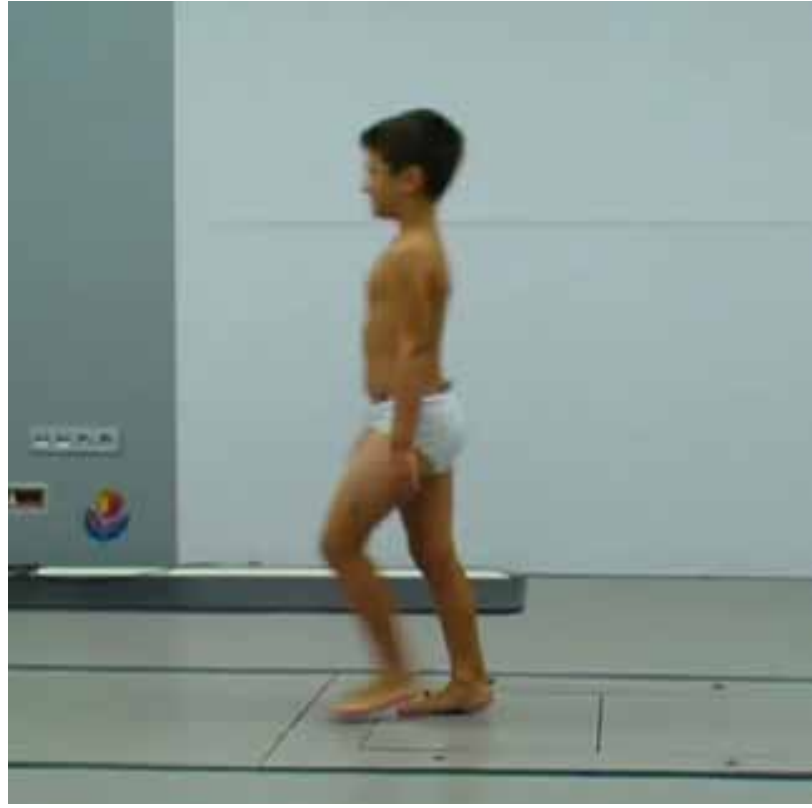

Şekil 7. Salınım ortası.

\section{FRONTAL PLAN}

Pelvis oblisitesi ve kalça abduktor zayıflığı değerlendirilir. Basan taraftaki kalça abduktorları kasılarak salınım fazındaki karşı pelvisin aşağı düşmesini engeller. Kalça abduktor (gluteus medius) zayıflı̆̆ Trendelenburg testi ile değerlendirilir. Ayrıca, ataksi gibi yürüme dengesinin bozulduğu durumlar en iyi frontal planda gözlemlenir (Şekil 9). ${ }^{3,4]}$

\section{TRANSVERS PLAN}

Transvers planda patella açısı, ayak ilerleme açısı ve üst ekstremitenin pozisyonu değerlendirilir. Yürüme döngüsü boyunca patellalar karşıya bakmalıdır. Ayak ilerleme açısı $10-15^{\circ}$ eksternalde olmalıdır. Eğer ayak ilerleme açısı internalde ise hasta femoral anteversiyon yönünden değerlendirilmelidir. Ayak ilerleme açısı aşııı eksternalde ise eksternal tibial torsiyon varlığı düşünülmelidir. Genu varus/valgus ve kalça adduktor spastisitesi (makaslama yürüyüşü) kontrol edilmelidir. Sabit fleksiyondaki üst ekstremite hemipleji için karakteristiktir ve aynı taraf alt ekstremite ile birlikte değerlendirilmelidir (Şekil 10). ${ }^{[2,4]}$

\section{ADIM UZUNLUĞU}

Normal yürümede sağ ve sol adım uzunlukları eşit olmalıdır. Adım uzunluğu; basma sonu fazındaki zayıf itme gücü, ilk salınım fazında zayıf kalça fleksör aktivitesi, salınım sonu fazında aşıı hamstring aktivitesi ve

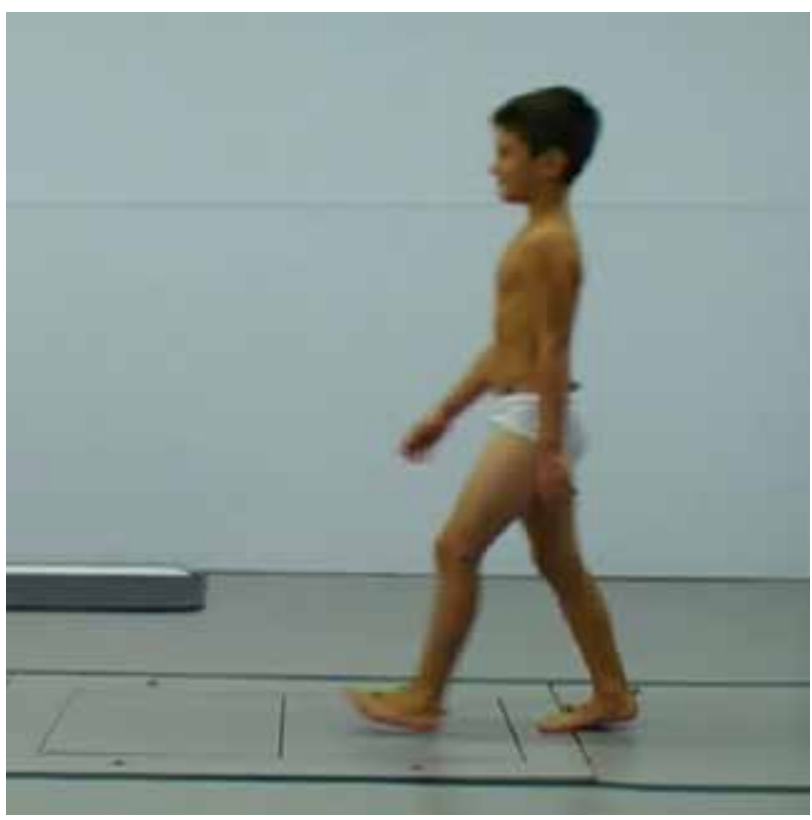

Şekil 8. Salınım sonu.

kontralateral ekstremitedeki azalmış kalça ve diz ekstansiyonun varlığında kısalır. ${ }^{[2-4]}$

Görsel yürüme analizi sistematik ve ayrıntılı olarak yapılırken değerlendirme formunun kullanılması yapılan işlemi kolaylaştırır ve hızlandırır (Tablo 1). Buna en iyi örnek Rancho Los Amigos Medical Centre Görsel Yürüme Değerlendirme Formu'dur. ${ }^{[1,4]}$ Bu formlar ile elde edilen verilerin sayısal olarak ifade edilebilmesi ve ölçülerek değerlendirilebilmesi için bazı skalalar geliştirilmiş̧ir. Hekim değerlendirme skalası (Physician Rating Scale) ve Edinburg Görsel Yürüme Analizi Testi (Edinburg Visual Gait Analysis Interval Testing) bunlardan bazılarıdır. ${ }^{[5]}$ Yapılan araştırmalarda bu testlerin orta derecede güvenilirliklerinin olduğu, gözlemci içi (intraobserver) güvenilirliklerinin mükemmel, gözlemciler arası (interobserver) güvenilirliklerinin ise zayıf olduğu saptanmıştır. ${ }^{[5]}$

Kawamura ve arkadaşları geriye dönük bir çalışmada spastik diplejik serebral palsi tanılı 50 hastanın görsel ve bilgisayarlı yürüme analizi verilerini karşılaştırdıklarında, görsel analizde sadece ilk temas sırasındaki diz eklem açısının ve basma ortası fazdaki pelvik oblisitenin güvenilir olarak değerlendirilebildiğini bildirmişlerdir. ${ }^{[6]}$

Mackey ve arkadaşları, 20 spastik diplejik serebral palsili hastanın görsel video kayıtları ve bilgisayarlı yürüme analizi verilerini değerlendirdikleri çalışmada ise; görsel video analizinde ilk temastaki ayak pozisyonu, basma ortası fazdaki diz ve ayak posizyonları ile basma fazındaki topuk kalkışının bilgisayarlı yürüme 


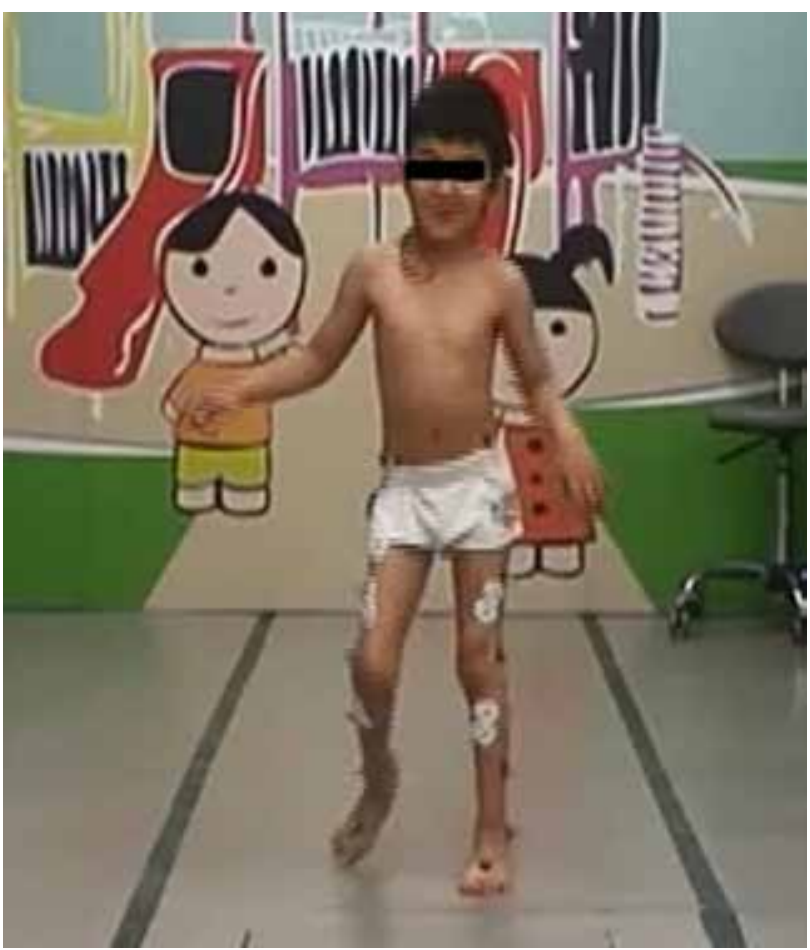

Şekil 9. Pelvik oblisite.

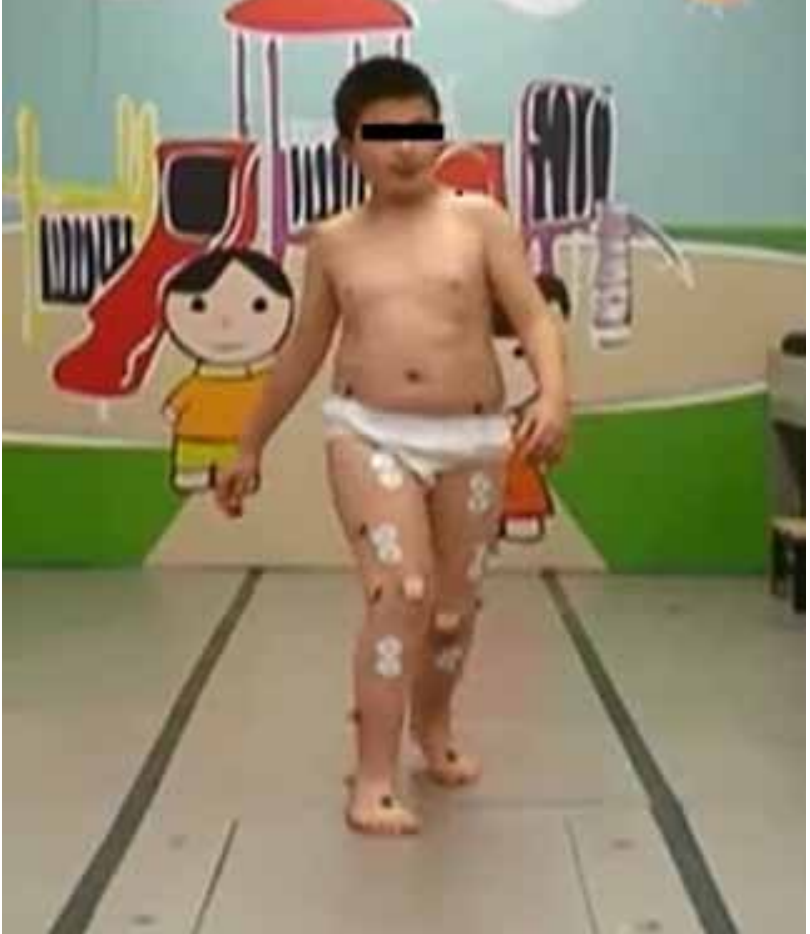

Şekil 10. Torsiyonel deformite.

Tablo 1. Basitleştirilmiş görsel yürüme analizi değerlendirme formu ${ }^{a}$

\begin{tabular}{|c|c|c|c|}
\hline Yürümenin fazları & Ayak/ayak bileği & Diz & Kalça/gövde \\
\hline Illk temas & $\begin{array}{l}\square \text { Nötral } \\
\square \text { Tüm taban } \\
\square \text { Ön ayak }\end{array}$ & $\begin{array}{l}\square \text { Ekstansiyon } \\
\square \text { Fleksiyon }\end{array}$ & \\
\hline Yüklenmenin kabulü & $\begin{array}{l}\square \text { Kontrollü plantar fleksiyon } \\
\square \text { Kontrollü hareket }\end{array}$ & $\begin{array}{l}\square 20^{\circ} \text { Fleksiyon } \\
\square \text { Ekstansiyon }\end{array}$ & \\
\hline Çift destek/ilerleme & $\begin{array}{l}\square 10^{\circ} \text { Dorsifleksiyon } \\
\square \text { Artmış dorsifleksiyon } \\
\square \text { Plantarfleksiyon }\end{array}$ & $\begin{array}{l}\square \text { Ekstansiyon } \\
\square \text { Sıçrama (jump knee) } \\
\square \text { Rekürvatum }\end{array}$ & $\begin{array}{l}\square 10^{\circ} \text { Ekstansiyon } \\
\square \text { Fleksiyon } \\
\square \text { Gövde fleksiyonu }\end{array}$ \\
\hline Parmak kalkışı & $\begin{array}{l}\square 20^{\circ} \text { Plantarfleksiyon } \\
\square \text { Ayak supinasyonu } \\
\square \text { Kontralateral adım uzunluğu }\end{array}$ & $\begin{array}{l}\square \text { Ekstansiyonda } \\
\square \text { Fleksiyonda }\end{array}$ & \\
\hline Salınım & $\begin{array}{l}\square \text { Ayağın yerden temasının } \\
\text { kesilmesi }\end{array}$ & $\begin{array}{l}\square 60^{\circ} \text { Fleksiyonda } \\
\square \text { Sert diz } \\
\square \text { Makaslama }\end{array}$ & $\begin{array}{l}\square \text { Stepaj } \\
\square \text { Trendelenburg }\end{array}$ \\
\hline
\end{tabular}

analizi verileriyle yüksek korrelasyon gösterdiğini bulmuşlardır. ${ }^{[7]}$

Krebs ve arkadaşları, yürüme bozukluğu olan ve ortez kullanan 15 çocuk hastanın dahil edildiği çalışmada; görsel video analizinin özellikle sagittal plandaki patolojierin tanımlanmasında uygun, ancak orta derecede güvenilir bir değerlendirme metodu olduğunu vurgulamışlardır. ${ }^{[8]}$
Sonuç olarak; görsel yürüme analizi tek başına uygulandığında güvenilirliği düşüktür ancak video analiz yazılımları ile güvenilirliği arttırılabilir. ${ }^{[9]}$ Kolay erişilebilir ve uygulanabilir olması, kayıtların tekrar tekrar alınmasına olanak sağlaması nedeniyle klinik takipte etkinliği kanıtlanmış bir yöntemdir. Ayrıca üç boyutlu bilgisayarlı yürüme analizi yapılabilen kliniklerde değerlendirmenin değişmez bir parçasıdır. 


\section{KAYNAKLAR}

1. Gage JR, Schwartz MH, Koop SE, Novacheck TF, editors. The Identification and Treatment of Gait Problems in Cerebral Palsy, 2nd ed. London: Mac Keith Press; 2009. p.198-202.

2. Miller F. Cerebral Palsy, 1st edition. Wilmington, DE: Springer; 2005. p.276.

3. Perry J, Burnfield JM. Gait Analysis: Normal and pathological function, 2nd ed. Thorofare, New Jersey: SLACK Incorporated; 2010. p.198-202.

4. Kirtley C. Clinical Gait Analysis: Theory and Practice, 1 st ed. London, UK: Elsevier Churchill Livingstone; 2006. p.267-79.

5. Maathuis KG, van der Schans $C P$, van Iperen $A$, Rietman HS, Geertzen JH. Gait in children with cerebral palsy: observer reliability of Physician Rating Scale and Edinburg Visual Gait Analysis Interval Testing Scale. J Pediatr Orthop 2005;25(3):268-72.
6. Kawamura CM, de Morais Filho MC, Barreto MM, de Paula Asa SK, Juliano Y, Novo NF. Comparison between visual and three-dimensional gait analysis in patients with spastic diplegic cerebral palsy. Gait Posture 2007;25(1):18-24.

7. Mackey HA, Lobb GL, Walt SE, Stott NS. Reliability and validity of the Observational Gait Scale in children with spastic diplegia. Dev Med Child Neurol 2003;45(1):4-11.

8. Krebs DE, Edelstein JE, Fishman S. Reliability of observational kinematic gait analysis. Phys Ther 1985;65(7):1027-33.

9. Borel S, Schneider P, Newman CJ. Video analysis software increases the interrater reliability of video gait assessments in children with cerebral palsy. Gait Posture 2011;33(4):727-9. CrossRef 